Article

\title{
Thermosensitive Hydrogel Mask Significantly Improves Skin Moisture and Skin Tone; Bilateral Clinical Trial
}

\author{
Anna Quattrone ${ }^{\dagger}$, Anna Czajka ${ }^{\dagger}$ and Sara Sibilla * \\ Minerva Research Labs Ltd., 1-6 Yarmouth Place, London W1J 7BU, UK; \\ aquattrone@minervalabs.com (A.Q.); annac@minervalabs.com (A.C.) \\ * Correspondence: ssibilla@minervalabs.com; Tel.: +44-20-3818-9471 \\ † These authors contributed equally to this work. \\ Academic Editors: Farid Menaa, Perry Xiao, Valdir A. Braga and Ali Barkat Khan \\ Received: 28 February 2017; Accepted: 24 May 2017; Published: 1 June 2017
}

\begin{abstract}
Objective: A temperature-sensitive state-changing hydrogel mask was used in this study. Once it comes into contact with the skin and reaches the body temperature, it uniformly and quickly releases the active compounds, which possess moisturizing, anti-oxidant, anti-inflammatory and regenerative properties. Methods: An open label clinical trial was conducted to evaluate the effects of the test product on skin hydration, skin tone and skin ageing. Subjects applied the product to one side of their face and underwent Corneometer ${ }^{\circledR}$ and Chromameter measurements, Visual assessment of facial skin ageing and facial photography. All assessments and Self-Perception Questionnaires (SPQ) were performed at baseline, after the first application of the test product and after four applications. Results: After a single treatment we observed an increase in skin moisturisation, an improvement of skin tone/luminosity and a reduction in signs of ageing, all statistically significant. After four applications a further improvement in all measured parameters was recorded. These results were confirmed by the subjects' own perceptions, as reported in the SPQ both after one and four applications. Conclusion: The hydrogel mask tested in this study is very effective in improving skin hydration, skin radiance and luminosity, in encouraging an even skin tone and in reducing skin pigmentation.
\end{abstract}

Keywords: hydrogel mask; skin; hydration; pigmentation; skin ageing; antioxidant; skin barrier

\section{Introduction}

The skin is the largest organ of the human body, it accounts for about $16 \%$ of its total weight [1] and plays a major role in maintaining homeostasis and environmental protection. It regulates the body temperature and the body fluid content, and represents the principal barrier to the external environment, for example, it protects against pathogenic agents and UV radiations [2]. Skin appearance and texture are highly influenced by the water content of the epidermis and the dermis, defined as skin hydration. The water in the skin can be present in the form of free or bound water molecules. In the stratum corneum, free water is able to diffuse from the skin to the outer environment, while bound water is associated with many other molecules, so-called "Natural Moisturizing Factors" [3]. Decreased hydration of the skin leads to a dry and scaly skin surface and it may cause skin irritation and inflammation, and different dermatological conditions [4-6]. Reduced moisture will also lead to loss of skin radiance and skin elasticity. The reduction in elasticity decreases skin's ability to retain its shape and this causes the formation of fine lines and wrinkles.

Skin hydration can be affected by endogenous factors, such as genetic components, hormonal changes and intrinsic ageing $[7,8]$. Notably, the natural ageing process results in the loss of hyaluronic 
acid (HA), one of the most important components of the extracellular matrix together with collagen and elastin. HA is a high-molecular-weight glycosaminoglycan (10-104 kDa) composed of repeating disaccharide units of $\mathrm{N}$-acetylglucosamine and glucuronic acid [9-11]. HA plays a key role in tissue hydration and moisture retention due to its ability to bind water molecules that can reach up to 1000-fold its molecular weight [12]. In the skin, HA is found in the dermis and in the epidermal intercellular spaces, and it is synthesized by fibroblasts, keratinocytes and other skin cells [12]. HA has a very fast turnover rate of 0.5 to a few (2-3) days [13] and its amount decreases with age. HA has been widely used as an anti-ageing cosmetic ingredient, both topically and orally.

Skin hydration can also be influenced by the diet and lifestyle factors, i.e., poor diet, alcohol, caffeine and cigarette consumption, each of reducing skin moisturisation $[14,15]$.

Lastly, environmental factors, such as air dryness and air conditioning, wind, cold weather and ultraviolet (UV) radiations, can also disrupt the water balance in the skin [16-19] and therefore cause dry skin. For example, exposure to UV radiations can lead to skin photo-damage and, as a consequence, to skin ageing as well as to skin cancer [20-22]. In particular, UV light is an external oxidative stressor on the skin and reactive oxygen species (ROS) are generated after UV exposure [23]. These, in turn, activate mitogen-activated-protein kinase, nuclear factor kappa B and activator protein 1 metabolic pathways $[24,25]$. ROS also induce the secretion of pro-inflammatory cytokines by both keratinocytes and fibroblasts [26] and of matrix degrading metallo-proteinases, enzymes involved in most of the phenotypes related to photo-damage [27]. As visible consequences, UV radiations can cause sunburn, erythema, skin inflammation, pigmentation, dehydration and appearance of wrinkles. Facial skin is the most UV exposed area and it is susceptible to premature skin ageing. Recent studies suggest that sunscreen application provides only limited protection against the long-term effects of UV exposure [28]. Other strategies should be considered to attenuate ROS signalling and inflammation pathways. For example, topical application of cosmetic products containing botanical extract with anti-oxidant and anti-inflammatory as well as hydrating properties have proved to be effective against photo-damage and photo-ageing [29-33].

We have conducted a clinical trial in order to evaluate the effects of a hydrogel mask on skin properties such as skin hydration, skin tone (erythema/pigmentation) and skin ageing. The test product has been specifically formulated with a water soluble bio-matrix, glycerine, hyaluronic acid, pearl extract and a blend of botanical extracts, known to contribute to skin hydration and to counteract the signs of ageing, and to possess anti-oxidant and anti-inflammatory properties. These ingredients can act as moisturising and protective agents to help prevent the clinical signs of photo-ageing and improve skin quality.

Hydrogels are three-dimensional polymer networks known to have effective moisturising properties [34-36] due to their high water content. Their hydrophilic base creates a matrix to the skin, which allows high efficacy in delivering active ingredients into the skin [36-38]. Thermosensitive hydrogels are especially utilized for localized, controlled and continuous delivery of active compounds, based on a shift in their conformation, solubility and hydrophilic/hydrophobic balance due to thermal stimuli [36]. Their formulation and properties can be adjusted to match the bioactive ingredient's release kinetics; therefore, these are of great interest in skin care and skin therapy as transdermal delivery systems $[36,37,39]$. In this study, we have used a temperature-sensitive state-changing hydrogel, which, once it comes into contact with the skin and reaches the body temperature, uniformly and quickly releases the active compounds into the skin. Moreover, HA (included in the hydrogel mask formulation) has recently been introduced as a vehicle for topical application of drugs to the skin. It has been demonstrated in fact that HA is absorbed from the surface of the skin and passes rapidly through the epidermis. This may allow HA-associated drugs to be carried within the skin in relatively high concentration, at least as far as the deeper layers of the dermis [40].

In this clinical trial, we show that the hydrophilic hydrogel base together with the penetrating abilities of hyaluronan create a mask which is able to deliver the active ingredients into the skin, leading to an improvement in skin hydration, skin tone and skin appearance. 


\section{Materials and Methods}

\subsection{Test Product}

The Test product considered in this study is the GOLD COLLAGEN ${ }^{\circledR}$ HYDROGEL MASK (GCHM), which is manufactured by GENIC Co., Ltd. (Seong-nam, Korea) for MINERVA Research Labs Ltd. (London, UK). GCHM is a temperature-sensitive state-changing soluble hydrogel mask system (Patent No. 0506543, European Patent No 1653921, US 8,663,664B2). The GCHM is formulated as shown in Table 1 . The test product was applied onto the face following the manufacturer's instructions, for a maximum of $30 \mathrm{~min}$ before being removed.

Table 1. GOLD COLLAGEN ${ }^{\circledR}$ HYDROGEL MASK list of ingredients.

\begin{tabular}{l}
\hline Ingredients \\
\hline Water \\
Glycerin \\
1,2-Hexanediol \\
Ceratonia Siliqua Gum \\
Chondrus Crispus (Carrageenan) Extract \\
Lactobacillus Ferment \\
Scutellaria Baicalensis Root Extract \\
Camellia Sinensis Leaf Extract \\
Artemisia Princeps Leaf Extract \\
Houttuynia Cordata Extract \\
Citrus Junos Fruit Extract \\
Ricinus Communis (Castor) Seed Oil \\
Caprylyl Glycol \\
Butylene Glycol \\
Phenoxyethanol \\
Pearl Extract \\
Sodium Hyaluronate \\
Dipotassium Glycyrrhizate \\
PEG-60 Hydrogenated Castor Oil \\
Disodium EDTA \\
Arginine \\
Fragrance
\end{tabular}

\subsection{Ethics}

The study conformed to the requirements of the 1964 Declaration of Helsinki and its subsequent amendments [41]. The study was carried out within the spirit of the ICH Guidelines on Good Clinical Practice, 1996 [42] and other recognised guidelines. Subjects were informed of the nature, purpose and known risk of the study both orally and in writing and gave their written informed consent before participating in the study.

\section{Study Design}

The first part of the study was a pilot in-house open label clinical trial. Subjects who met the eligibility criteria, enlisted below, were recruited. The subjects were assessed for their skin appearance and were asked to complete a Self-Perception Questionnaire (SPQ) at the beginning of the trial (T0) and after the $30 \mathrm{~min}$ test product application (T1). The effects of the treatment on skin hydration and skin tone (erythema) were measured using digital photography system, DermaView-PRO (OptoBioMed ${ }^{\text {TM }}$, Wonju-Si, Korea), at baseline (T0) and after the 30 min treatment (T1).

\subsection{Inclusion Criteria}

Female subjects between 20 and 65 years old. 
- All ethnic background.

- Healthy subjects and those with no current or previous medical history.

- Subjects psychologically able to understand the study related information and to give a written informed consent.

- $\quad$ Subjects with healthy BMI (between 19 and 30).

\subsection{Exclusion Criteria}

- The use of a topical medication containing steroids to treat skin diseases more than once a month.

- Hypersensitive skin.

- Subjects with severe skin-related pathologies and abnormalities, such as severe acne, erythema, broken skin, eczema, cancer.

- Skin peeling, botox or other wrinkle removal procedure done within a month from the start of the current trial.

- Subject with specific allergies or hypersensitivity to any of the ingredients present in the products to be tested.

\subsection{Restrictions}

- The subjects could continue to use their usual moisturisers, cosmetics, wash products and toiletries. Any changes to the brand or use of new products were recorded.

- Subjects were advised to report any over-the-counter medication to study investigator.

- Subjects were advised to avoid the application of other face mask or the use of collagen-based supplements during the trial.

The second part of the study was an open label clinical trial carried out by an independent Contract Research Organization (CRO) in the UK. This was a bilateral (half-face), left vs. right (treated vs. untreated) clinical study. The test product was applied weekly for 4 weeks. Subjects who met the eligibility criteria, enlisted below, were recruited. At baseline (T0) subjects underwent Corneometer ${ }^{\circledR}$ assessments for moisturisation, Chromameter assessments for skin tone/luminosity, expert visual assessment of facial skin ageing and facial photography. All assessments and photography were performed again 20 min after removal of the test product (first application, T1) and at the end of the study (4 applications, T2). Subjects were also asked to complete a SPQ post treatment after the first application (T1) and at the end of the study (T2).

\subsection{Inclusion Criteria}

- Healthy female volunteers, aged 40 years+, with ageing skin (dehydrated or hyper pigmented skin).

- Subject has signed a written Informed Consent; consents to facial photography.

- Subject exhibits moderate to advanced photo-ageing according to the Glogau scale.

\subsection{Exclusion Criteria}

- Subject is pregnant, nursing, or planning to become pregnant.

- Heavy alcohol consumption in the opinion of the investigator.

- A fever in the last $12 \mathrm{~h}$, prior to start of the study.

- Significant past medical history of hepatic, cancerous, multiple sclerosis, high blood pressure, renal, thrombosis/phlebitis, cardiac, pulmonary, digestive, haematological, neurological, locomotor or psychiatric disease, which in the opinion of the Investigator would compromise the safety of the subject.

- Insulin-dependent diabetes. 
- Concurrent medication likely to affect the response to the test article or confuse the results of the study including anti-depressants, botox/collagen fillers and collagen-based food supplements in the last 1 to 3 months.

- Participation in an anti-ageing study in the last 28 days.

- Pacemaker.

- Photo Epilepsy for Light Therapy.

- People with chronic skin conditions such as psoriasis, eczema, melasma, etc.

\subsection{Prohibitions and Restrictions}

- Subject agrees to attend all visits with a clean face, free of makeup and hair tied back.

- Subject agrees to keep to their usual facial skin cleansing and moisturising products, and make up for the duration of the study.

- Subject agrees to only use the test article and no other facial mask products for the duration of the study.

- Avoid Area: metal pins/plates or silicone implants in face, open cuts and abrasions, skin and eye infections, severe sunburn, conjunctivitis, styes, and in flare eczema/psoriasis on face.

\section{Instrumental Assessment}

\subsection{DermaView-PRO}

DermaView-PRO (OptoBioMed $\left.{ }^{\mathrm{TM}}\right)$ is a digital skin image analysis system, which uses a high resolution digital camera (Canon EOS DSLR 400 D/18-55 mm, 10.0 Mega Pixel, Tokyo, Japan). By using specialized image acquisition, it provides real-time polarization, non-polarization and UV images. Six images of the face were taken in total ( 2 front and 4 profiles) using 2 different modes. Cross polarization images (CPI) was used for the analysis between the dermis and epidermis layers to measure skin tone (erythema). UV images were taken to analyse the degree of skin moisture.

\subsection{Corneometer ${ }^{\circledR}$ Measurements for Skin Hydration}

Moisturisation measurements to study the humectant properties of the test product were performed using the Corneometer ${ }^{\circledR}$ CM825 (Courage and Khazaka, Cologne, Germany). This instrument relies on the dielectric constant, a physical property of water, which is relatively high and as such will affect the capacitance of a capacitor. Any change in the dielectric constant due to skin moisture variations alters the capacitance of the precision capacitor in the instrument. These variations were detected electronically and were converted into a value by the Corneometer ${ }^{\circledR}$. A 15 min warm-up period was allowed before using the Corneometer ${ }^{\circledR}$. Three measurements were made using the probe attachment of the Corneometer ${ }^{\circledR}$ at each of the test sites (cheek area), between each assessment the probe attachment of the Corneometer ${ }^{\circledR}$ was pressed onto a dry tissue. The next assessment was not performed until a value of 5 or less was displayed by the instrument. Subjects were in a controlled environment (at a temperature of $22{ }^{\circ} \mathrm{C} \pm 2{ }^{\circ} \mathrm{C}$ and at a relative humidity of $45 \pm 5 \%$ ) for at least $30 \mathrm{~min}$ prior to any assessments being performed.

\subsection{Chromameter CR300 Measurements for Skin Tone/Luminosity}

Instrumental measurements of skin tone and colour were performed using the Chromameter CR300 (Courage and Khazaka, Germany) on the cheek area of the face. The measuring head of the CR-300 uses diffuse illumination $/ 0^{\circ}$ viewing geometry. A pulsed xenon arc (PXA) lamp inside a mixing chamber provides diffuse, uniform lighting over the $8 \mathrm{~mm}$-diameter specimen area. Only the light reflected perpendicular to the specimen surface is collected by the optical fibre cable for colour analysis. This instrument measures the amount of light reflected from the skin and quantifies this into a numerical value using the $L^{*} a^{*} b^{*}$ colour scale, where $L^{*}(100)$ equates to total white and $L^{*}(0)$ equates 
to total black. Therefore, the $L^{*}$ value is inversely proportional to the Fitzpatrick visual scale of skin tone. The instrument was allowed to warm up for $30 \mathrm{~min}$ prior to use.

\section{Visual Assessment}

Subjects were evaluated under standard lighting conditions by an expert according to the Glogau scale of aged skin, at each assessment point.

\subsection{Photography}

High resolution digital images for all subjects were captured using a professional Canon EOS DSLR camera under standard lighting conditions against a blank background by a professional photographer. Images were taken of each test site (facial: 1 frontal and 2 profile, one of each side of the face).

\subsection{Statistics}

GraphPad Prism 5 (GraphPad Software, La Jolla, CA, USA) was used to analyse the DermaView-PRO data. Distribution of the data was assessed using Kolmogorov-Smirnov test. The analysis was performed using Wilcoxon matched-pairs signed rank test both for skin tone (erythema) and hydration results. The statistical analysis for the Corneometer ${ }^{\circledR}$, Chromameter and visual assessment data was run on the Microsoft Excel platform using Student's $t$-Test and one-way ANOVA. Data are presented as means \pm standard error of the mean (SEM). Differences where $P<0.05$ were considered to be statistically significant.

\section{Results}

\subsection{Pilot Study}

Study Population

A total of 62 female healthy volunteers, aged between 21 and 65 years old (average age 37.7 years) were enrolled and completed the study. The subjects were of various ethnic origins, mainly Caucasians (Table 2), with variable skin characteristics, based on visual assessment of skin hydration, skin sensitivity, presence of wrinkles and skin pigmentation (Table 3). Most of the subjects presented a skin type III (Table 4) based on Fitzpatrick scale and showed a mild photo-aged skin (Table 5) based on Glogau scale. Supplementary Table S1 shows the analysis of the subjects' lifestyle. None of the subjects experienced adverse events.

Table 2. Analysis of the ethnicity of the pilot study subjects.

\begin{tabular}{ccc}
\hline Ethnicity & $\mathbf{n}^{\circ}$ & $\mathbf{\%}$ \\
\hline Caucasian & 44 & 70.9 \\
Asian & 7 & 11.3 \\
Black & 4 & 6.5 \\
Latin-American & 4 & 6.5 \\
Middle-Eastern & 3 & 4.8 \\
\hline
\end{tabular}

Table 3. Analysis of the skin type of the pilot study subjects, based on the subjects' self-assessment of skin hydration, skin sensitivity, visible wrinkles and skin pigmentation.

\begin{tabular}{ccc}
\hline Skin Type & & $\%$ \\
\hline & Oily & 9.7 \\
\multirow{2}{*}{ Hydration } & Normal & 16.1 \\
& Dry & 21 \\
& Mixed & 53.2 \\
\hline
\end{tabular}


Table 3. Cont.

\begin{tabular}{|c|c|c|}
\hline \multicolumn{2}{|c|}{ Skin Type } & $\%$ \\
\hline \multirow{3}{*}{ Sensitivity } & Sensitive & 33.8 \\
\hline & Resistant & 6.5 \\
\hline & Normal & 59.7 \\
\hline \multirow{3}{*}{ Wrinkles } & Tight & 61.3 \\
\hline & Normal & 35.5 \\
\hline & Wrinkled & 3.2 \\
\hline \multirow{3}{*}{ Pigmentation } & Normal & 53.2 \\
\hline & Pigmented & 22.6 \\
\hline & Non-pigmented & 24.2 \\
\hline
\end{tabular}

Table 4. Analysis of the skin type of the pilot study subjects, based on Fitzpatrick scale.

\begin{tabular}{cc}
\hline Skin Colour/ Fitzpatrick Scale & \% \\
\hline I & 1.6 \\
II & 22.6 \\
III & 43.5 \\
IV & 25.8 \\
V & 1.6 \\
VI & 4.9 \\
\hline
\end{tabular}

Table 5. Analysis of the photo-ageing of the pilot study subjects, based on Glogau scale.

\begin{tabular}{cc}
\hline Photo-ageing & \% \\
\hline Mild & 89 \\
Moderate & 8 \\
Obvious & 3 \\
\hline
\end{tabular}

\subsection{Hydration}

UV digital skin colour images were acquired from 62 subjects before (T0) and after (T1) the test product application. Qualitative and quantitative analyses of skin hydration were performed using DermaVision software. A highly statistically significant increase in skin hydration $(+3.6, \sim 4 \%$, $P<0.0001$ ) was observed after one treatment with the hydrogel mask tested in this study (Figure 1).

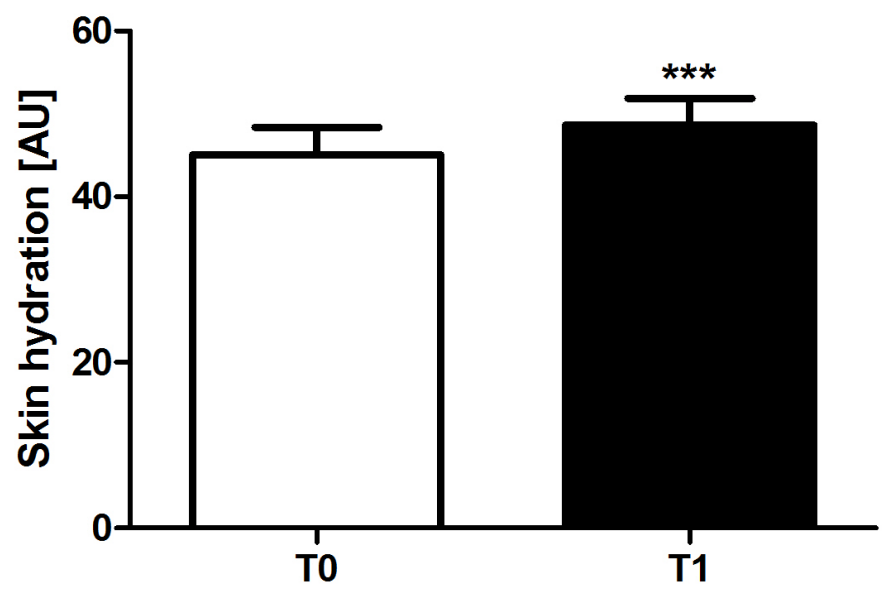

Figure 1. Skin hydration at baseline (T0) and after one application of the test product (T1) in the pilot study subjects. Data acquired using DermaView-PRO, a digital skin analysis photography system. *** indicates $P<0.0001$. 


\subsection{Skin Tone (Erythema)}

Cross-polarized digital skin colour images were acquired from 62 subjects before (T0) and after (T1) the test product application. Both qualitative and quantitative analyses of skin erythema/skin tone were performed using DermaVision software. A statistically significant improvement in skin tone (left profile: $+6.4, \sim 21 \%, P=0.02$; right profile: $+6.5, \sim 19 \% P=0.04$ ) was observed after one treatment with the hydrogel mask tested in this study, both for the left and the right profiles (Figure 2).

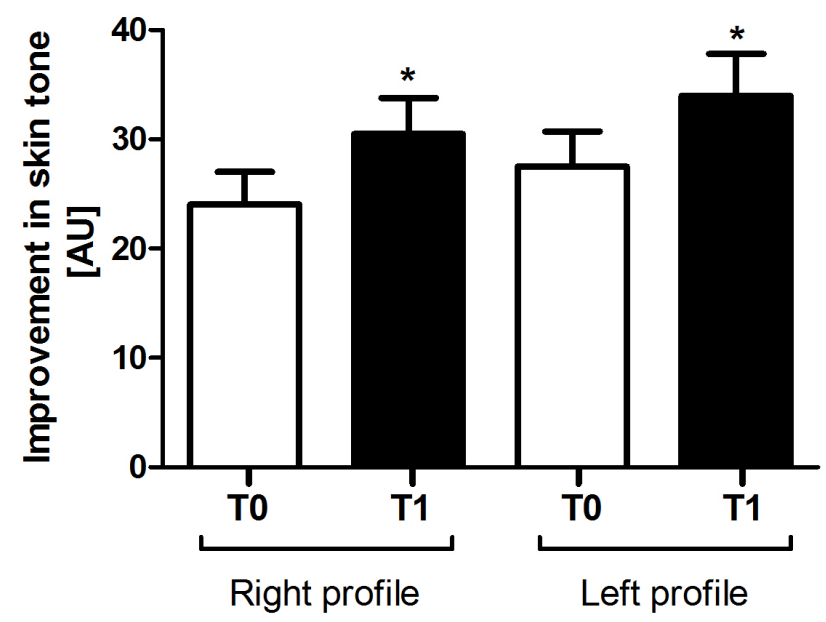

Figure 2. Skin tone at baseline (T0) and after one application of the test product (T1) in the pilot study subjects. Right and left profiles are shown. * indicates $P<0.05$.

\subsection{Self-Perception Questionnaires}

The results obtained by instrumental assessment were confirmed by the subjects' perception as reported in the SPQ. Combining the top 2 responses ('strongly agree' and 'agree'), SPQ results showed that more than $96 \%$ of the subjects felt their skin was more hydrated after the treatment with the test product. They also felt their skin was smoother $(85 \%)$, softer $(84 \%)$, more supple $(80 \%)$, healthier $(77 \%)$, more radiant $(71 \%)$, more youthful (54.8\%) and firmer (54.8\%) (Figure 3 and Supplementary Table S2). Notably, more than $90-95 \%$ of the subjects appreciated the product, which underlines a very good patients' compliance (data not shown).

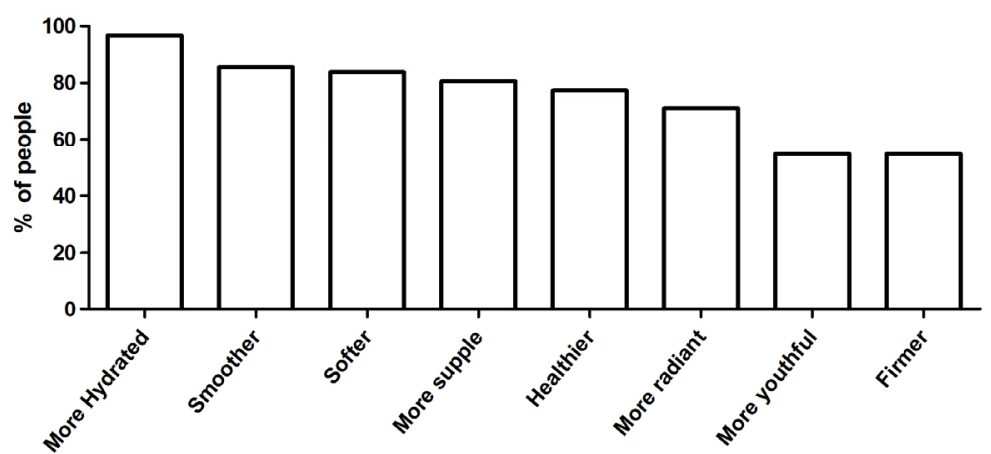

Figure 3. Self-Perception Questionnaire responses of the pilot study subjects after one application of the test product. 


\subsection{Clinical Trial}

\subsubsection{Study Population}

For this part of the study 31 subjects were recruited and 30 completed the study. One subject withdrew for reasons not related to the use of the test product. The age range for the subjects was between 40 and 76 years old (average age 54.4 years). None of the subjects experienced adverse effects.

\subsubsection{Corneometer ${ }^{\circledR}$}

As assessed by Corneometer ${ }^{\circledR}$ analysis, after a single application (T1) of the hydrogel mask tested in this study, a highly statistically significant increase in skin hydration $(+74.03 \%, P<0.0001)$ was observed in the treated part of the face (left profile) compared to baseline (T0) (Figure 4). After 4 applications, treatment with the test product produced an even higher improvement of skin moisturisation and the difference between the baseline (T0) and the end of the treatment (T2) was even more statistically significant $(+79.24 \%, P<0.0001)$ (Figure 4$)$. To note, statistically significant differences were observed also between untreated and treated areas both after 1 (T1) and after 4 mask applications (T2) $(P<0.0001)$ (Figure 4). No statistically significant differences were observed between baseline (T0), 1 application (T1) and 4 applications (T2) of the test product in the not treated area (right profile) (Figure 4). Raw data for Corneometer ${ }^{\circledR}$ assessment are shown in Supplementary Table S3.

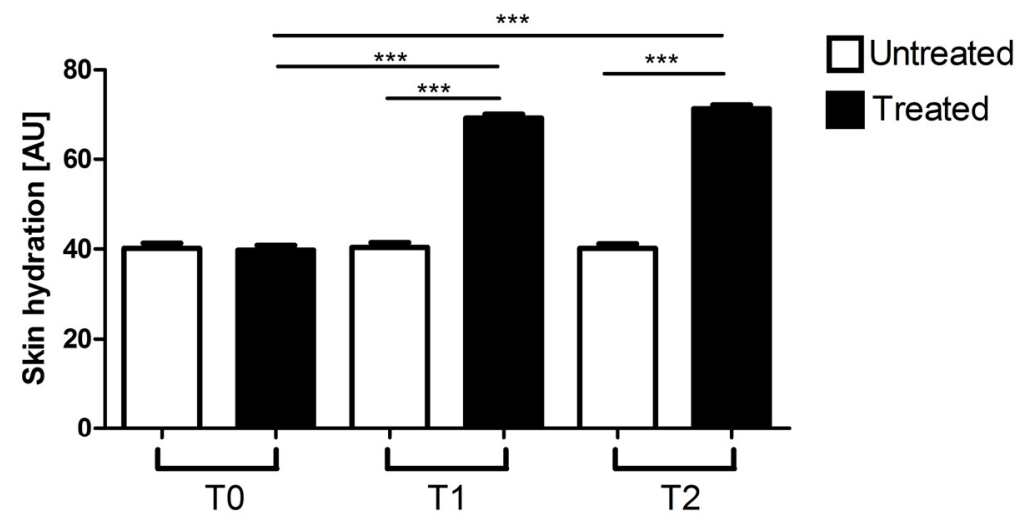

Figure 4. Skin hydration at baseline (T0), after one application (T1) and after 4 applications (T2) of the test product in the clinical trial subjects. Untreated (in white) and treated (in black) sides are shown. *** indicates $P<0.0001$.

\subsubsection{Chromameter}

As assessed by Chromameter analysis, after a single application (T1) of the hydrogel mask tested in this study, a statistically significant improvement in skin tone/luminosity $(+8.9 \%, P<0.05)$ was observed in the treated part of the face (left profile) compared to baseline (T0) (Figure 5). After 4 applications, treatment with the test product produced a much greater improvement in skin tone/luminosity and the difference between the baseline (T0) and the end of the treatment (T2) was highly statistically significant $(+18.39 \%, P<0.0001)$ (Figure 5$)$. To note, statistically significant differences were observed also between untreated and treated areas both after 1 (T1) and after 4 mask applications (T2) $(P<0.05$ and $P<0.0001$ respectively) (Figure 5). No statistically significant differences in skin tone were observed between baseline (T0), 1 application (T1) and 4 applications (T2) of the test product in the not treated area (right profile) (Figure 5). Raw data for Chromameter assessment are reported in Supplementary Table S4. 


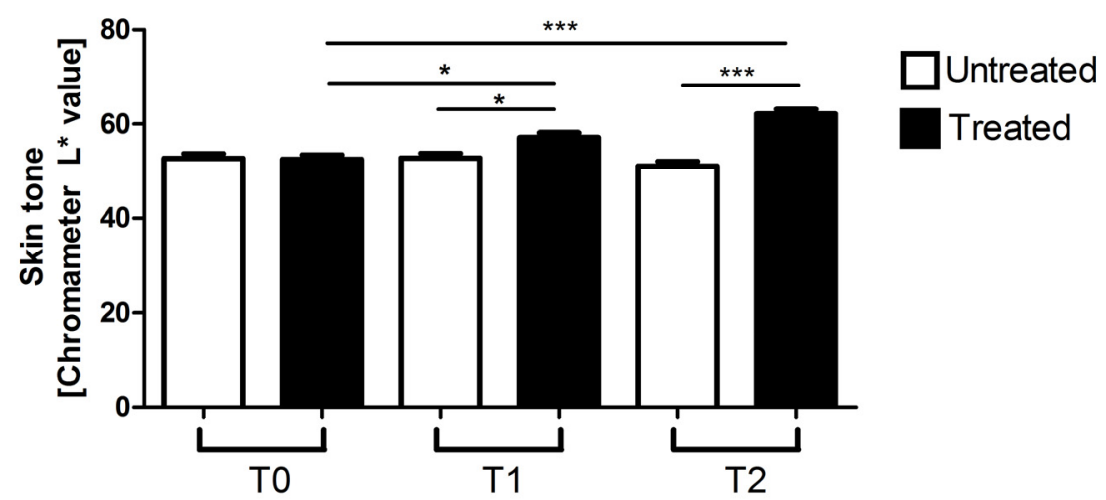

Figure 5. Skin tone at baseline (T0), after one application (T1) and after 4 applications (T2) of the test product in the clinical trial subjects. Untreated (in white) and treated (in black) sides are shown. *** indicates $P<0.0001$ * indicates $P<0.05$.

\subsection{Visual Assessment}

Visual grading analysis demonstrated that a single application of the hydrogel mask tested in this study can produce a $-24.74 \%$ reduction in signs of ageing and the difference between baseline (T0) and 1 treatment (T1) was highly statistically significant $(P<0.001)$ (Figure 6). After 4 mask applications, a $-32.89 \%$ reduction in signs of ageing was observed, and the difference between baseline (T0) and treatment (T2) was highly statistically significant $(P<0.0001)$ (Figure 6). To note, statistically significant differences were observed also between untreated and treated areas both after 1 (T1) and after 4 mask applications (T2) $(P<0.001$ and $P<0.0001$ respectively) (Figure 6). No statistically significant differences were observed between baseline (T0), 1 application (T1) and 4 applications of the test product (T2) in the not treated area (right profile) (Figure 6). Raw data for Visual assessment are reported in Supplementary Table S5.

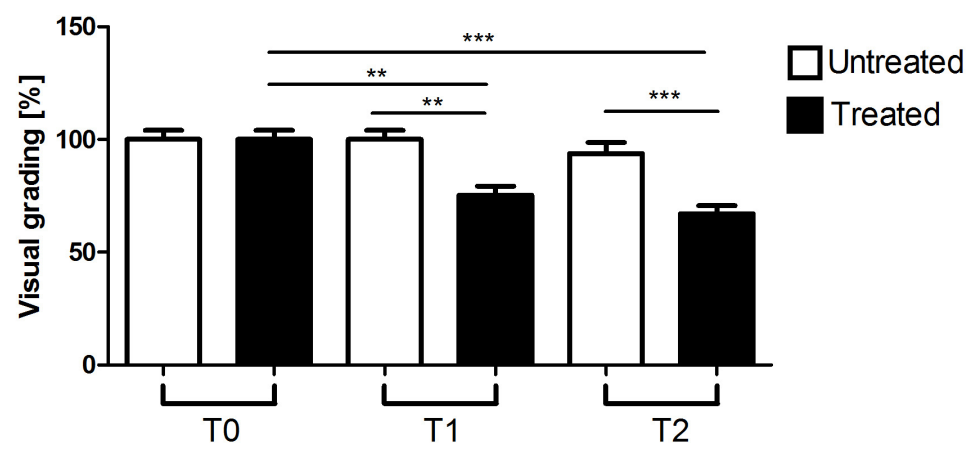

Figure 6. Visual grading of signs of ageing at baseline (T0), after one application (T1) and after 4 applications (T2) of the test product in the clinical trial subjects. Untreated (in white) and treated (in black) sides are shown. ${ }^{* *}$ indicates $P<0.0001,{ }^{* *}$ indicates $P<0.001$.

\subsubsection{Photography}

High resolution digital images were captured for all subjects at baseline (T0), after 1 application (T1) and after 4 applications (T2) of the test product. Images were taken of each test site (facial: 1 frontal and 2 profile, left profile (treated) and right profile (untreated)). Representative examples of three subjects are shown in Figure 7. 

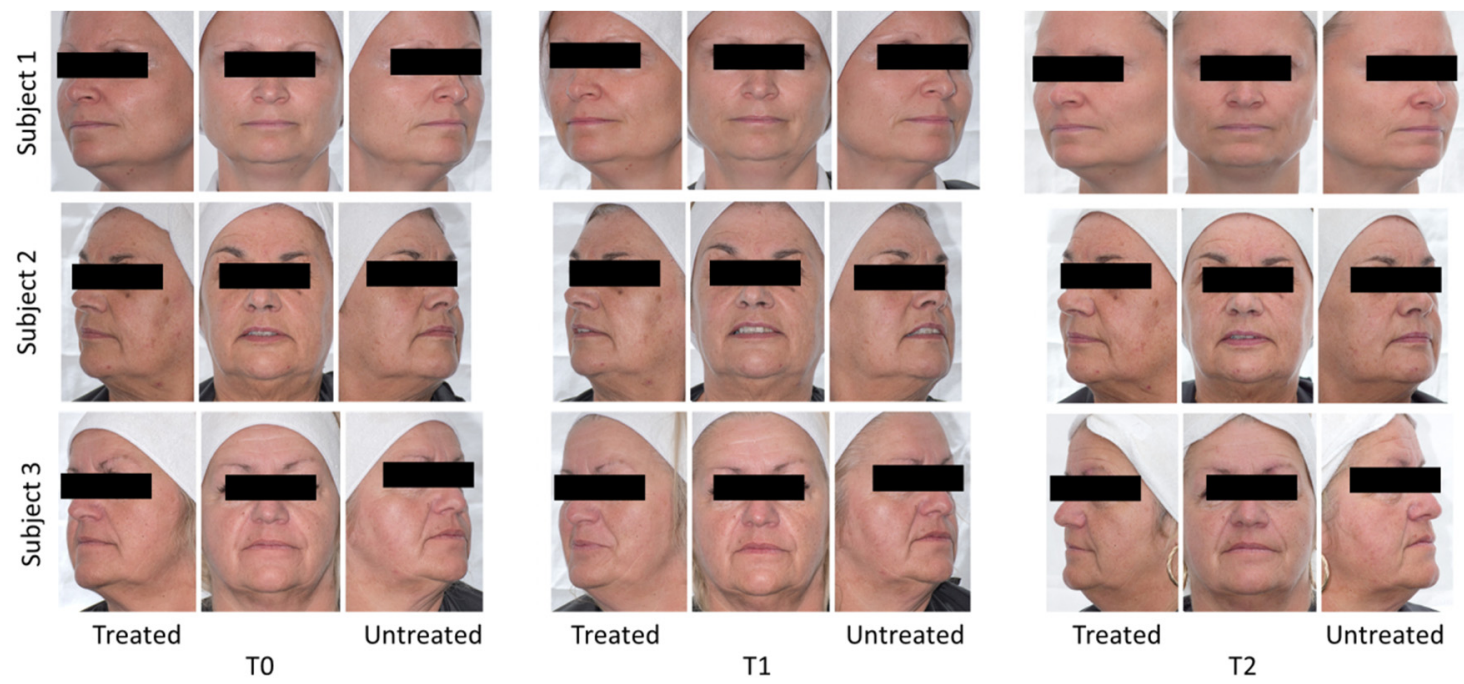

Figure 7. Representative images of three clinical trial subjects at baseline (T0), after one application (T1) and after 4 applications (T2) of the test product. Treated (left profile) and untreated (right profile) sides are shown.

\subsubsection{Self-Perception Questionnaires}

Results of the SPQ after 1 hydrogel mask application (T1) showed the product to be highly favourable with the top 2 responses ('strongly agree' and 'agree') combined being greater than 85\% for most of the attributes considered: less tired $(96.7 \%)$, more even skin tone $(93.5 \%)$, brighter $(93.5 \%)$, younger looking skin $(93.5 \%)$, healthier $(100 \%)$, more radiant $(93.5 \%)$, fresher $(87 \%)$, plumper $(90.3 \%)$, more moisturised $(100 \%) .51 .5 \%$ of women, which is still the majority, agreed that after using the product they had a reduction in fine lines and wrinkles. Only one response did not show a majority: $25.8 \%$ of women agreed after using the product they had a reduction in pigmentation spots (Figure 8 , Supplementary Table S6). Nevertheless, SPQ responses after 4 mask applications (T2) showed that $74.1 \%$ of women agreed that after using the product they had a reduction in pigmentation spots, suggesting an overall improvement in skin pigmentation with continuous use. All the other responses, at the end of the study (T2), showed the product to be highly favourable with the top 2 responses ('strongly agree' and 'agree') combined being greater than 95\%: less tired (100\%), more even skin tone $(100 \%)$, brighter $(100 \%)$, younger looking skin $(96.7 \%)$, healthier $(100 \%)$, more radiant $(100 \%)$, fresher $100 \%)$, plumper $(96.6 \%)$, more moisturised $(100 \%)$. To note, $80.6 \%$ of women agreed that after using the product they had a reduction in fine lines and wrinkles (Figure 8, Supplementary Table S6). All in all, the subjects noticed a further improvement after 4 applications of the test product. Moreover, the majority of the subjects appreciated the product, which underlines a very good patients' compliance (Supplementary Table S6). 


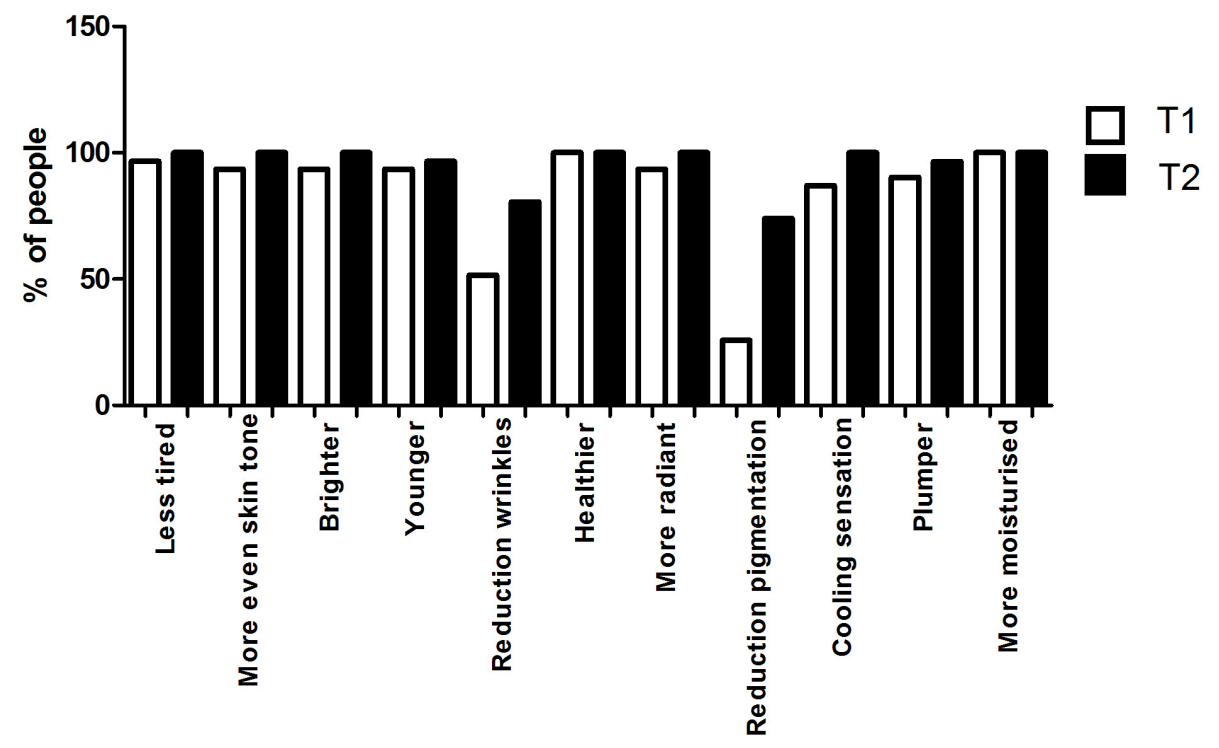

Figure 8. Self-Perception Questionnaire responses of clinical trial subjects after one application (T1) and after 4 applications (T2) of the test product.

\section{Discussion}

One of the major causes of skin deterioration is the reduction of skin water content. A dehydrated skin appears scaly, dull, less plump and elastic, and more prone to the appearance of fine lines and wrinkles. It can also become itchy and inflamed. On the top of intrinsic ageing process and life style factors, environmental conditions such as cold weather or UV radiations can lead to skin dehydration, inflammation, uneven pigmentation and premature ageing. To maintain a healthy and young looking skin, it is important to keep the skin hydrated and to protect it against the action of free radicals, especially facial skin, the most exposed to environmental factors.

The active ingredients contained in the hydrogel mask tested in this study (glycerine, hyaluronic acid, pearl extract, Camellia sinensis leaf extract, Scutellaria baicalensis root extract, Ricinus communis seed oil, Houttuynia cordata extract, Citrus junus fruit extract, Artemisia princeps leaf extract) were all carefully selected for their proved moisturising, anti-oxidant, anti-inflammatory and regenerative properties.

Regarding its moisturizing properties, the mask tested in this study is a hydrogel based mask with high glycerine content, which is a humectant compound that attracts water to the stratum corneum $[43,44]$. Several studies have demonstrated that glycerine promotes skin hydration and can also increase skin permeability [45-48].

Similar properties have been attributed to hyaluronic acid, an important active ingredient of the test product. Notably, a study on hairless mice and humans established that HA is absorbed through the superficial layers of the skin and can pass through the epidermis [40]. Moreover, HA was shown that can be used as a vehicle for topical application of drugs to the skin [40,49-51]. Topical application of different molecular weights of HA formulations has been shown to lead to a significant improvement in skin hydration and elasticity and to a significant reduction of wrinkle depth $[52,53]$.

It was very interesting to see the properties of these two compounds, present in the test product, well reflected in the results of this study. First of all, remarkable effects were achieved already after 1 mask application, which confirms that glycerine and HA were very effective to promote the delivery of the active ingredients contained in this hydrogel composition into the skin. Secondly, a highly statistically significant increase in skin hydration was observed both in the pilot and in the clinical study, after 1 and 4 applications of the test product.

Other active ingredients contained in the test product were pearl extract and a blend of botanical extracts which present moisturising, anti-inflammatory, anti-oxidant and wound healing properties. 
The pearl extract has been shown to promote wound healing due to its ability to stimulate fibroblast mitosis, collagen deposition and the production of tissue inhibitor of metalloproteinase-1 [54,55]. Moreover, pearl extract has anti-inflammatory and anti-apoptotic effects on UVB irradiated human keratinocyte cells [56], and has also anti-oxidant activity [57].

Camellia sinensis leaf extract is a green tea extract that contains polyphenols, known to be effective free radical scavengers, and other compounds that could also provide benefits to the skin. Clinical studies have demonstrated that topical application of green tea extracts significantly reduced face wrinkles [58], increased skin moisture and reduced skin roughness [59]. Prolonged 60 day topical treatment with green tea extract significantly improved skin elasticity in human subjects [60]. In an in vivo study, Camellia sinensis extract showed high potential in wound healing activity. In fact, the newly formed tissue was shown to contain less inflammatory cells and more collagen fibres, compared to wounds dressed with vehicle only [61].

Scutellaria baicalensis root extract, also known as baikal skullcap, contains very powerful flavonoids, including baicalin, baicalein, wogonin, and wogonoside [62-65]. These compounds have an anti-inflammatory effect, similar to prednisolone [66-68] and can be potential therapeutic agents against acne-induced skin inflammation [69]. Moreover, wogonin was proved to differentially regulate the expression of inflammation-associated genes in vivo and it became a useful therapeutic agent for skin inflammatory diseases due to its modulation of the expression of pro-inflammatory molecules [70]. The flavonoids contained in S. baicalensis have also strong anti-oxidant properties [71]. An extract from this plant was shown to possess protective activity against oxidation induced by UV light [72-74] and it could be used as an additive in cosmetic products for UV protection [75]. Moreover, it was shown that topical baicalin application mitigates DNA photo-damage [76] and baicalein exerts anti-ageing effects through attenuating oxidative stress [77].

Ricinus communis seed oil, or Castor oil, was shown to have scavenging activity against free radicals. It has been utilized to treat inflammatory related diseases including wounds, sores and boils [78,79], and it was proved to have great potential when applied as antibacterial in wound dressings [80].

Houttuynia cordata, which is called "dokudami" in Japanese, is known to be a potent anti-oxidant herb. Houttuynia cordata extract may be beneficial for treating ROS-related photo-ageing and barrier-disrupted skin conditions [81].

Citros junos fruit extract, known as yuzu, provides an important dietary source of anti-oxidant compounds with rich polyphenol and limonoid contents [82], and it has also anti-inflammatory properties $[83,84]$.

Last, Artemisia princeps leaf extract, known as mugwort, can be used as a therapeutic agent for inflammatory skin diseases through the inhibition of inflammatory mediator release from macrophages and inflammatory cytokine production in inflamed tissues [85].

The statistically significant improvement in skin tone/luminosity and the reduction of skin inflammation (erythema score) and pigmentation may suggest that the hydrogel mask tested in this study could be used after exposure to UV radiation, to sooth the inflammatory response. Moreover, it could be proposed as post treatment therapy after aesthetic procedures such as laser or peeling, to decrease skin inflammation and promote wound healing. However, additional studies on the anti-inflammatory, anti-oxidant and regenerative properties of the active ingredients should be performed to demonstrate this further.

Although the results from this trial clearly show an increase in moisturisation and an improvement in the skin tone, however because of the study design (bilateral design: treated area vs. not treated area) and the mask delivery platform itself (a film and the gel in it: the gel itself consists of active ingredients such as glycerine and HA), we cannot conclude which combination of the active ingredients was the most effective. It will be interesting to investigate further the effects of glycerine and HA vs. botanical ingredients plus glycerine and HA using other delivery systems, like e.g., water-in-oil emulsions, which can be combined with botanical extracts creating successful delivery systems, as shown by other research groups $[86,87]$. 
No skin hypersensitivity cases were reported during the duration of this clinical trial. This is consistent with the data available in the literature and the in vivo and in vitro studies performed on the single ingredients (present in the test product), even after continuous application [32,35,56,59,60,88-90].

\section{Conclusions}

In conclusion, the hydrogel mask tested in this study is a very effective product to improve skin hydration, skin radiance and luminosity, to encourage an even skin tone, reducing skin pigmentation, and to promote young looking skin, reducing the signs of ageing. These effects can be obtained after a single treatment; however, prolonged use of the test product promotes even better results. Interestingly, all the instrumental results were confirmed by the subjects' perception in the Self-Perception Questionnaires. Subjects' product appreciation was also very high, which reflects in an excellent compliance during the study and their desire to use the product on a weekly basis in the future.

Supplementary Materials: The following are available online at www.mdpi.com/2079-9284/4/2/17/s1, Table S1: Analysis of the lifestyle of the pilot study subjects, Table S2: Self-Perception Questionnaire responses of the pilot study subjects after one application of the test product, Table S3: Raw data for Corneometer ${ }^{\circledR}$ assessment, Table S4: Raw data for Chromameter assessment, Table S5: Raw data for Visual assessment, Table S6: Self-Perception Questionnaire responses of the clinical trial subjects after one application (T1) and 4 applications (T2) of the test product.

Acknowledgments: The GOLD COLLAGEN ${ }^{\circledR}$ HYDROGEL MASK used in this study was provided by MINERVA Research Labs (London, UK). The study was funded by MINERVA Research Labs (London, UK). We would like to thank Martin Godfrey and Licia Genovese for their time and expertise in critically reviewing the manuscript.

Author Contributions: Sara Sibilla, Anna Czajka conceived and designed the experiments; Anna Czajka performed the experiments in the pilot study; Anna Czajka and Anna Quattrone analysed the data; Anna Quattrone wrote the paper. The CRO analysed independently and reported the data from the clinical trial to Anna Quattrone, Anna Czajka and Sara Sibilla, removing any perceived conflict of interest.

Conflicts of Interest: The authors certify that there is no conflict of interest regarding the material discussed in this manuscript.

\section{References}

1. Rush, A.; Muir, M. Maintaining skin integrity bariatric patients. Br. J. Community Nurs. 2012, 17, $154-159$. [CrossRef] [PubMed]

2. Freinkel, R.K.; Woodley, D.T. The Biology of the Skin; Partheon Publishing Group Limited: Casterton, Carnforth, UK, 2001.

3. Manfredini, M.; Mazzaglia, G.; Ciardo, S.; Simonazzi, S.; Farnetani, F.; Longo, C.; Pellacani, G. Does skin hydration influence keratinocyte biology? In vivo evaluation of microscopic skin changes induced by moisturizers by means of reflectance confocal microscopy. Skin Res. Technol. Off. J. Int. Soc. Bioeng. Skin 2013, 19, 299-307.

4. Serup, J.; Blichmann, C. Epidermal hydration of psoriasis plaques and the relation to scaling. Measurement of electrical conductance and transepidermal water loss. Acta Derm. Venereol. 1987, 67, 357-359. [PubMed]

5. Berardesca, E.; Fideli, D.; Borroni, G.; Rabbiosi, G.; Maibach, H. In vivo hydration and water-retention capacity of stratum corneum in clinically uninvolved skin in atopic and psoriatic patients. Acta Derm. Venereol. 1990, 70, 400-404. [PubMed]

6. Sator, P.G.; Schmidt, J.B.; Honigsmann, H. Comparison of epidermal hydration and skin surface lipids in healthy individuals and in patients with atopic dermatitis. J. Am. Acad. Dermatol. 2003, 48, 352-358. [CrossRef] [PubMed]

7. Dal'Belo, S.E.; Gaspar, L.R.; Maia Campos, P.M. Moisturizing effect of cosmetic formulations containing aloe vera extract in different concentrations assessed by skin bioengineering techniques. Skin Res. Technol. Off. J. Int. Soc. Bioeng. Skin 2006, 12, 241-246. [CrossRef] [PubMed]

8. Flynn, T.C.; Petros, J.; Clark, R.E.; Viehman, G.E. Dry skin and moisturizers. Clin. Dermatol. 2001, 19, 387-392. [CrossRef] 
9. Shimada, E.; Matsumura, G. Viscosity and molecular weight of hyaluronic acids. J. Biochem. 1975, 78, 513-517. [CrossRef] [PubMed]

10. Tammi, R.; Saamanen, A.M.; Maibach, H.I.; Tammi, M. Degradation of newly synthesized high molecular mass hyaluronan in the epidermal and dermal compartments of human skin in organ culture. J. Investig. Dermatol. 1991, 97, 126-130. [CrossRef] [PubMed]

11. Scott, J.E. Secondary structures in hyaluronan solutions: Chemical and biological implications. In Ciba Foundation Symposium 143-The Biology of Hyaluronan; Evered, D., Whelan, J., Eds.; John Wiley \& Sons, Ltd.: Chichester, UK, 2007; pp. 281-285.

12. Laurent, T.C.; Fraser, J.R. Hyaluronan. FASEB J. 1992, 6, 2397-2404. [PubMed]

13. Fraser, J.R.; Laurent, T.C.; Laurent, U.B. Hyaluronan: Its nature, distribution, functions and turnover. Intern. Med. 1997, 242, 27-33. [CrossRef]

14. Naylor, E.C.; Watson, R.E.; Sherratt, M.J. Molecular aspects of skin ageing. Maturitas 2011, 69, $249-256$. [CrossRef] [PubMed]

15. Baumann, L. Skin ageing and its treatment. J. Pathol. 2007, 211, 241-251. [CrossRef] [PubMed]

16. Thorleifsson, A.; Wulf, H.C. Emollients and the response of facial skin to a cold environment. Br. J. Dermatol. 2003, 148, 1149-1152. [CrossRef] [PubMed]

17. Egawa, M.; Oguri, M.; Kuwahara, T.; Takahashi, M. Effect of exposure of human skin to a dry environment. Skin Res. Technol. Off. J. Int. Soc. Bioeng. Skin 2002, 8, 212-218. [CrossRef]

18. Kligman, L.H. Photoaging. Manifestations, prevention, and treatment. Dermatol. Clin. 1986, 4, 517-528. [PubMed]

19. Guercio-Hauer, C.; Macfarlane, M.D.; Deleo, V.A. Photodamage, photoaging and photoprotection of the skin. Am. Fam. Physician 1994, 50, 327-332. [PubMed]

20. Kohl, E.; Steinbauer, J.; Landthaler, M.; Szeimies, R.M. Skin ageing. J. Eur. Acad. Dermatol. Venereol. 2011, 25, 873-884. [CrossRef] [PubMed]

21. Altmayer, P.; Hoffmann, H.K.; Stucker, M. Skin Cancer and UV Radiation; Springer: New York, NY, USA, 1997.

22. Moyal, D.; Fourtanier, A. Photoaging; Rigel, D.S., Weiss, R.A., Lim, H.W., Dover, J.S., Eds.; Marcel Dekker Inc.: New York, NY, USA, 2004; Chapter 2; p. 15.

23. Zastrow, L.; Ferrero, L.; Herrling, T.; Groth, N. Integrated sun protection factor: A new sun protection factor based on free radicals generated by UV irradiation. Skin Pharmacol. Physiol. 2004, 17, 219-231. [CrossRef] [PubMed]

24. Muthusamy, V.; Piva, T.J. The UV response of the skin: A review of the MAPK, NFkappaB and TNFalpha signal transduction pathways. Arch. Dermatol. Res. 2010, 302, 5-17. [CrossRef] [PubMed]

25. Rittie, L.; Fisher, G.J. UV-light-induced signal cascades and skin aging. Ageing Res. Rev. 2002, 1, 705-720. [CrossRef]

26. Averbeck, M.; Beilharz, S.; Bauer, M.; Gebhardt, C.; Hartmann, A.; Hochleitner, K.; Kauer, F.; Voith, U.; Simon, J.C.; Termeer, C. In situ profiling and quantification of cytokines released during ultraviolet B-induced inflammation by combining dermal microdialysis and protein microarrays. Exp. Dermatol. 2006, 15, 447-454. [CrossRef] [PubMed]

27. Quan, T.; Qin, Z.; Xia, W.; Shao, Y.; Voorhees, J.J.; Fisher, G.J. Matrix-degrading metalloproteinases in photoaging. J. Investig. Dermatol. Symp. Proc. 2009, 14, 20-24. [CrossRef] [PubMed]

28. Van der Pols, J.C.; Williams, G.M.; Pandeya, N.; Logan, V.; Green, A.C. Prolonged prevention of squamous cell carcinoma of the skin by regular sunscreen use. Cancer Epidemiol. Biomark. Prev. A Publ. Am. Assoc. Cancer Res. Cosponsored Am. Soc. Prev. Oncol. 2006, 15, 2546-2548. [CrossRef] [PubMed]

29. Hughes-Formella, B.; Wunderlich, O.; Williams, R. Anti-inflammatory and skin-hydrating properties of a dietary supplement and topical formulations containing oligomeric proanthocyanidins. Skin Pharmacol. Physiol. 2007, 20, 43-49. [CrossRef] [PubMed]

30. Thomas, N.V.; Kim, S.K. Beneficial effects of marine algal compounds in cosmeceuticals. Mar. Drugs 2013, 11, 146-164. [CrossRef] [PubMed]

31. Gianeti, M.D.; Maia Campos, P.M. Efficacy evaluation of a multifunctional cosmetic formulation: The benefits of a combination of active antioxidant substances. Molecules 2014, 19, 18268-18282. [CrossRef] [PubMed]

32. Mercurio, D.G.; Wagemaker, T.A.; Alves, V.M.; Benevenuto, C.G.; Gaspar, L.R.; Maia Campos, P.M. In vivo photoprotective effects of cosmetic formulations containing UV filters, vitamins, ginkgo biloba and red algae extracts. J. Photochem. Photobiol. B 2015, 153, 121-126. [CrossRef] [PubMed] 
33. Ratz-Lyko, A.; Arct, J.; Pytkowska, K. Moisturizing and antiinflammatory properties of cosmetic formulations containing centella asiatica extract. Indian J. Pharm. Sci. 2016, 78, 27-33. [CrossRef] [PubMed]

34. Leite e Silva, V.R.; Schulman, M.A.; Ferelli, C.; Gimenis, J.M.; Ruas, G.W.; Baby, A.R.; Velasco, M.V.; Taqueda, M.E.; Kaneko, T.M. Hydrating effects of moisturizer active compounds incorporated into hydrogels: In vivo assessment and comparison between devices. J. Cosmet. Dermatol. 2009, 8, 32-39. [CrossRef] [PubMed]

35. Wynne, A.; Whitefield, M.; Dixon, A.J.; Anderson, S. An effective, cosmetically acceptable, novel hydro-gel emollient for the management of dry skin conditions. J. Dermatol. Treat. 2002, 13, 61-66. [CrossRef] [PubMed]

36. Ullah, F.; Othman, M.B.; Javed, F.; Ahmad, Z.; Md Akil, H. Classification, processing and application of hydrogels: A review. Mater. Sci. Eng. C Mater. Biol. Appl. 2015, 57, 414-433. [CrossRef] [PubMed]

37. Lee, S.G.; Kim, S.R.; Cho, H.I.; Kang, M.H.; Yeom, D.W.; Lee, S.H.; Lee, S.; Choi, Y.W. Hydrogelbased ultra-moisturizing cream formulation for skin hydration and enhanced dermal drug delivery. Biol. Pharm. Bull. 2014, 37, 1674-1682. [CrossRef] [PubMed]

38. Li, Z.; Guan, J. Thermosensitive hydrogels for drug delivery. Expert Opin. Drug Deliv. 2011, 8, 991-1007. [CrossRef] [PubMed]

39. Wu, X.; Wu, Y.; Ye, H.; Yu, S.; He, C.; Chen, X. Interleukin-15 and cisplatin co-encapsulated thermosensitive polypeptide hydrogels for combined immuno-chemotherapy. J. Control. Release 2017, 255, 81-93. [CrossRef] [PubMed]

40. Brown, T.J.; Alcorn, D.; Fraser, J.R. Absorption of hyaluronan applied to the surface of intact skin. J. Investig. Dermatol. 1999, 113, 740-746. [CrossRef] [PubMed]

41. World Medical, A. World medical association declaration of helsinki: Ethical principles for medical research involving human subjects. JAMA 2013, 310, 2191-2194.

42. The International Conference on Harmonisation of Technical Requirements for the Registration of Pharmaceuticals for Human Use (ICH). Good Clinical Practice. Available online: http:/ /ec.europa.eu/ health//sites/health/files/files/eudralex/vol-10/3cc1aen_en.pdf (accessed on 28 May 2017).

43. Lazar, A.P.; Lazar, P. Dry skin, water, and lubrication. Dermatol. Clin. 1991, 9, 45-51. [PubMed]

44. Draelos, Z.D. Therapeutic moisturizers. Dermatol. Clin. 2000, 18, 597-607. [CrossRef]

45. Korponyai, C.; Szel, E.; Behany, Z.; Varga, E.; Mohos, G.; Dura, A.; Dikstein, S.; Kemeny, L.; Eros, G. Effects of locally applied glycerol and xylitol on the hydration, barrier function and morphological parameters of the skin. Acta Derm. Venereol. 2017, 97, 182-187. [CrossRef] [PubMed]

46. Alber, C.; Buraczewska-Norin, I.; Kocherbitov, V.; Saleem, S.; Loden, M.; Engblom, J. Effects of water activity and low molecular weight humectants on skin permeability and hydration dynamics-A double-blind, randomized and controlled study. Int. J. Cosmet. Sci. 2014, 36, 412-418. [CrossRef] [PubMed]

47. Bjorklund, S.; Engblom, J.; Thuresson, K.; Sparr, E. Glycerol and urea can be used to increase skin permeability in reduced hydration conditions. Eur. J. Pharm. Sci. Off. J. Eur. Fed. Pharm. Sci. 2013, 50, 638-645. [CrossRef] [PubMed]

48. Ventura, S.A.; Kasting, G.B. Dynamics of glycerine and water transport across human skin from binary mixtures. Int. J. Cosmet. Sci. 2016, 39, 165-178. [CrossRef] [PubMed]

49. Brown, M.B.; Jones, S.A. Hyaluronic acid: A unique topical vehicle for the localized delivery of drugs to the skin. Eur. Acad. Dermatol. Venereol. 2005, 19, 308-318. [CrossRef] [PubMed]

50. Weindl, G.; Schaller, M.; Schafer-Korting, M.; Korting, H.C. Hyaluronic acid in the treatment and prevention of skin diseases: Molecular biological, pharmaceutical and clinical aspects. Skin Pharmacol. Physiol. 2004, 17, 207-213. [CrossRef] [PubMed]

51. Laugier, J.P.; Shuster, S.; Rosdy, M.; Csoka, A.B.; Stern, R.; Maibach, H.I. Topical hyaluronidase decreases hyaluronic acid and CD44 in human skin and in reconstituted human epidermis: Evidence that hyaluronidase can permeate the stratum corneum. Br. J. Dermatol. 2000, 142, 226-233. [CrossRef] [PubMed]

52. Pavicic, T.; Gauglitz, G.G.; Lersch, P.; Schwach-Abdellaoui, K.; Malle, B.; Korting, H.C.; Farwick, M. Efficacy of cream-based novel formulations of hyaluronic acid of different molecular weights in anti-wrinkle treatment. J. Drugs Dermatol. 2011, 10, 990-1000. [PubMed]

53. Lee, D.H.; Oh, I.Y.; Koo, K.T.; Suk, J.M.; Jung, S.W.; Park, J.O.; Kim, B.J.; Choi, Y.M. Improvement in skin wrinkles using a preparation containing human growth factors and hyaluronic acid serum. J. Cosmet. Laser Ther. 2015, 17, 20-23. [CrossRef] [PubMed] 
54. Li, Y.C.; Chen, C.R.; Young, T.H. Pearl extract enhances the migratory ability of fibroblasts in a wound healing model. Pharm. Biol. 2013, 51, 289-297. [CrossRef] [PubMed]

55. Jian-Ping, D.; Jun, C.; Yu-Fei, B.; Bang-Xing, H.; Shang-Bin, G.; Li-Li, J. Effects of pearl powder extract and its fractions on fibroblast function relevant to wound repair. Pharm. Biol. 2010, 48, 122-127. [CrossRef] [PubMed]

56. Yang, Y.L.; Chang, C.H.; Huang, C.C.; Liu, H.W. Anti-inflammation and anti-apoptosis effects of pearl extract gel on UVB irradiation HaCaT cells. Biomed. Mater. Eng. 2015, 26 (Suppl. S1), S139-S145. [CrossRef] [PubMed]

57. Lijun You, Y.L.; Zhao, H.; Regenstein, J.; Zhao, M.; Ren, J. Purification and characterization of an antioxidant protein from pearl oyster (Pinctada fucata martensii). J. Aquat. Food Prod. Technol. 2014, 24, 661-671.

58. Hong, Y.H.; Jung, E.Y.; Shin, K.S.; Yu, K.W.; Chang, U.J.; Suh, H.J. Tannase-converted green tea catechins and their anti-wrinkle activity in humans. J. Cosmet. Dermatol. 2013, 12, 137-143. [CrossRef] [PubMed]

59. Gianeti, M.D.; Mercurio, D.G.; Campos, P.M. The use of green tea extract in cosmetic formulations: Not only an antioxidant active ingredient. Dermatol. Ther. 2013, 26, 267-271. [CrossRef] [PubMed]

60. Mahmood, T.; Akhtar, N.; Khan, B.A.; Shoaib Khan, H.M.; Saeed, T. Changes in skin mechanical properties after long-term application of cream containing green tea extract. Aging Clin. Exp. Res. 2011, 23, 333-336. [CrossRef] [PubMed]

61. Hajiaghaalipour, F.; Kanthimathi, M.S.; Abdulla, M.A.; Sanusi, J. The effect of camellia sinensis on wound healing potential in an animal model. Evid. Based Complement. Altern. Med. 2013, 2013, 386734. [CrossRef] [PubMed]

62. Li, H.B.; Chen, F. Isolation and purification of baicalein, wogonin and oroxylin a from the medicinal plant scutellaria baicalensis by high-speed counter-current chromatography. J. Chromatogr. A 2005, 1074, 107-110. [CrossRef] [PubMed]

63. You, J.; Gao, S.; Jin, H.; Li, W.; Zhang, H.; Yu, A. On-line continuous flow ultrasonic extraction coupled with high performance liquid chromatographic separation for determination of the flavonoids from root of scutellaria baicalensis georgi. J. Chromatogr. A 2010, 1217, 1875-1881. [CrossRef] [PubMed]

64. Liu, G.; Ma, J.; Chen, Y.; Tian, Q.; Shen, Y.; Wang, X.; Chen, B.; Yao, S. Investigation of flavonoid profile of scutellaria bacalensis georgi by high performance liquid chromatography with diode array detection and electrospray ion trap mass spectrometry. J. Chromatogr. A 2009, 1216, 4809-4814. [CrossRef] [PubMed]

65. Li, C.; Zhou, L.; Lin, G.; Zuo, Z. Contents of major bioactive flavones in proprietary traditional chinese medicine products and reference herb of radix scutellariae. J. Pharm. Biomed. Anal. 2009, 50, 298-306. [CrossRef] [PubMed]

66. Chung, C.P.; Park, J.B.; Bae, K.H. Pharmacological effects of methanolic extract from the root of scutellaria baicalensis and its flavonoids on human gingival fibroblast. Planta Medica 1995, 61, 150-153. [CrossRef] [PubMed]

67. Lim, H.; Son, K.H.; Chang, H.W.; Kang, S.S.; Kim, H.P. Inhibition of chronic skin inflammation by topical anti-inflammatory flavonoid preparation, ato formula. Arch. Pharmacal Res. 2006, 29, 503-507. [CrossRef]

68. Huang, W.H.; Lee, A.R.; Yang, C.H. Antioxidative and anti-inflammatory activities of polyhydroxyflavonoids of scutellaria baicalensis GEORGI. Biosci. Biotechnol. Biochem. 2006, 70, 2371-2380. [CrossRef] [PubMed]

69. Tsai, P.J.; Huang, W.C.; Hsieh, M.C.; Sung, P.J.; Kuo, Y.H.; Wu, W.H. Flavones isolated from scutellariae radix suppress propionibacterium acnes-induced cytokine production in vitro and in vivo. Molecules 2016, 21, 15. [CrossRef] [PubMed]

70. Chi, Y.S.; Lim, H.; Park, H.; Kim, H.P. Effects of wogonin, a plant flavone from scutellaria radix, on skin inflammation: In vivo regulation of inflammation-associated gene expression. Biochem. Pharmacol. 2003, 66, 1271-1278. [CrossRef]

71. Gao, Z.; Huang, K.; Yang, X.; Xu, H. Free radical scavenging and antioxidant activities of flavonoids extracted from the radix of scutellaria baicalensis georgi. Biochim. Biophys. Acta 1999, 1472, 643-650. [CrossRef]

72. Gabrielska, J.; Oszmianski, J.; Zylka, R.; Komorowska, M. Antioxidant activity of flavones from scutellaria baicalensis in lecithin liposomes. Z. Naturforschung C J. Biosci. 1997, 52, 817-823.

73. Bochorakova, H.; Paulova, H.; Slanina, J.; Musil, P.; Taborska, E. Main flavonoids in the root of scutellaria baicalensis cultivated in europe and their comparative antiradical properties. Phytother. Res. 2003, 17, 640-644. [CrossRef] [PubMed] 
74. Wozniak, D.; Lamer-Zarawska, E.; Matkowski, A. Antimutagenic and antiradical properties of flavones from the roots of scutellaria baicalensis georgi. Die Nahr. 2004, 48, 9-12. [CrossRef] [PubMed]

75. Seok, J.K.; Kwak, J.Y.; Choi, G.W.; An, S.M.; Kwak, J.H.; Seo, H.H.; Suh, H.J.; Boo, Y.C. Scutellaria radix extract as a natural UV protectant for human skin. Phytother. Res. 2016, 30, 374-379. [CrossRef] [PubMed]

76. Bing-Rong, Z.; Song-Liang, J.; Xiao, E.C.; Xiang-Fei, L.; Bao-Xiang, C.; Jie, G.; Dan, L. Protective effect of the baicalin against DNA damage induced by ultraviolet B irradiation to mouse epidermis. Photodermatol. Photoimmunol. Photomed. 2008, 24, 175-182. [CrossRef] [PubMed]

77. Gao, L.; Duan, D.D.; Zhang, J.Q.; Zhou, Y.Z.; Qin, X.M.; Du, G.H. A bioinformatic approach for the discovery of antiaging effects of baicalein from scutellaria baicalensis GEORGI. Rejuvenation Res. 2016. [CrossRef] [PubMed]

78. Nemudzivhadi, V.; Masoko, P. In vitro assessment of cytotoxicity, antioxidant, and anti-inflammatory activities of ricinus communis (euphorbiaceae) leaf extracts. Evid. Based Complement. Altern. Med. 2014, 2014, 625961. [CrossRef] [PubMed]

79. Lomash, V.; Parihar, S.K.; Jain, N.K.; Katiyar, A.K. Effect of solanum nigrum and ricinus communis extracts on histamine and carrageenan-induced inflammation in the chicken skin. Cell. Mol. Biol. 2010, 56 (Suppl. 56), OL1239-OL1251. [PubMed]

80. Diez-Pascual, A.M.; Diez-Vicente, A.L. Wound healing bionanocomposites based on castor oil polymeric films reinforced with chitosan-modified ZnO nanoparticles. Biomacromolecules 2015, 16, 2631-2644. [CrossRef] [PubMed]

81. Doi, K.; Mitoma, C.; Nakahara, T.; Uchi, H.; Hashimoto-Hachiya, A.; Takahara, M.; Tsuji, G.; Nakahara, M.; Furue, M. Antioxidant houttuynia cordata extract upregulates filaggrin expression in an aryl hydrocarbon-dependent manner. Hukuoka Acta Medica 2014, 105, 205-213. [PubMed]

82. Kim, S.Y.; Shin, K.S. Evaluation of physiological activities of the citron (Citrus junos Sieb. Ex TANAKA) seed extracts. Prev. Nutr. Food Sci. 2013, 18, 196-202. [CrossRef] [PubMed]

83. Minamisawa, M.; Yoshida, S.; Uzawa, A. The functional evaluation of waste yuzu (Citrus junos) seeds. Food Funct. 2014, 5, 330-336. [CrossRef] [PubMed]

84. Hirota, R.; Roger, N.N.; Nakamura, H.; Song, H.S.; Sawamura, M.; Suganuma, N. Anti-inflammatory effects of limonene from yuzu (Citrus junos Tanaka) essential oil on eosinophils. J. Food Sci. 2010, 75, H87-H92. [CrossRef] [PubMed]

85. Yun, C.; Jung, Y.; Chun, W.; Yang, B.; Ryu, J.; Lim, C.; Kim, J.H.; Kim, H.; Cho, S.I. Anti-inflammatory effects of artemisia leaf extract in mice with contact dermatitis in vitro and in vivo. Mediat. Inflam. 2016, 2016, 8027537. [CrossRef] [PubMed]

86. Sharif, A.; Akhtar, N.; Khan, M.S.; Menaa, A.; Menaa, B.; Khan, B.A.; Menaa, F. Formulation and evaluation on human skin of a water-in-oil emulsion containing muscat hamburg black grape seed extract. Int. J. Cosmet. Sci. 2015, 37, 253-258. [CrossRef] [PubMed]

87. Khan, B.A.; Akhtar, N.; Menaa, A.; Menaa, F. A novel Cassia fistula (L.)-based emulsion elicits skin anti-aging benefits in humans. Cosmetics 2015, 2, 368-383. [CrossRef]

88. Popa, E.G.; Carvalho, P.P.; Dias, A.F.; Santos, T.C.; Santo, V.E.; Marques, A.P.; Viegas, C.A.; Dias, I.R.; Gomes, M.E.; Reis, R.L. Evaluation of the in vitro and in vivo biocompatibility of carrageenan-based hydrogels. J. Biomed. Mater. Res. A 2014, 102, 4087-4097. [CrossRef] [PubMed]

89. Anonymous. Final Report on the Safety Assessment of Ricinus Communis (Castor) Seed Oil, Hydrogenated Castor Oil, Glyceryl Ricinoleate, Glyceryl Ricinoleate SE, Ricinoleic Acid, Potassium Ricinoleate, Sodium Ricinoleate, Zinc Ricinoleate, Cetyl Ricinoleate, Ethyl Ricinoleate, Glycol Ricinoleate, Isopropyl Ricinoleate, Methyl Ricinoleate, and Octyldodecyl Ricinoleate. Int. J. Toxicol. 2007, 26 (Suppl. S3), 31-77.

90. Kim, T.W.; Song, I.B.; Lee, H.K.; Kim, M.S.; Ham, S.H.; Cho, J.H.; Lim, J.H.; Yun, H.I. Assessment of dermal safety of scutellaria baicalensis aqueous extract topical application on skin hypersensitivity. Planta Med. 2013, 79, 959-962. [CrossRef] [PubMed]

(c) 2017 by the authors. Licensee MDPI, Basel, Switzerland. This article is an open access article distributed under the terms and conditions of the Creative Commons Attribution (CC BY) license (http:/ / creativecommons.org/licenses/by/4.0/). 